Journal of

International Logistics and Trade

\title{
A Practical Review of Green Supply Chain Management: Disciplines and Best Practices
}

\author{
Pourya Pourhejazy, Oh Kyoung Kwon* \\ Graduate School of Logistics, Inha University, Incheon, Korea
}

\begin{abstract}
ARTICLE INFO
Article history:

Received 2 August 2016

Accepted 23 August 2016

Keywords:

Supply chain

Green initiatives

Gest practices

GSCM disciplines

SC elements

ABSTRACT

Nowadays, climate change and environmental pollution have become major international concerns, in which logistics and manufacturing activities are playing the major role. In the past decade, more attention has been directed toward environmental issues than ever before. The Paris agreement is one of the most recent milestones in this regard. Due to local and international legislation, managers are highly encouraged to seek out sustainable innovations and strategies to reduce the negative impacts of their business activities. An array of academic and practical activities has been formed around the greening of the supply chain (SC). This paper attempts to review and classify green supply chain management (GSCM) disciplines and best practices from a practical point of view. The authors also investigate the different areas of application and review the GSCM practices in some well-known companies. On this basis, the paper disclose the superiority of Apple company over the other studied cases in applying green practices, particularly in the manufacturing and design areas, while the parcel delivery company has been quite active in the green transportation and green marketing. It is also shown that all of the reviewed cases have been successful in implementing green logistics initiatives thus far.
\end{abstract}

\section{Introduction}

In this day and age, environmental pollution caused by business activities has become a major issue. Global warming is the clear consequence of this phenomenon. Different stages of the supply chain (SC) are responsible for this concern, among which sourcing, manufacturing and logistics play the major role (Beamon 1999). Recently, organizations have started to implement green initiatives; however these activities are still based on the traditional "end-of-the-pipe" solutions, where they try to reduce the environmental impact of their activities after creating them. Instead, a more proactive approach involving the adoption of a green SC is needed to reduce environmental problems before they happen (Tareq Al Khidir 2006).

The new regulations adopted by governments, changes in consumers' attitudes, the limited amount of raw materials and resources, and overabundance of waste sites and the pollution arising from them are just some of the major drivers leading to the implementation of green practices. Considering the position of the business entities in the above-mentioned trend, they can contribute the most to making the SC process sustainable and act as a promoting leverage (Melville 2010). Green supply chain management (GSCM) has emerged to address the above-mentioned issues by involving the firms and extending their environmental responsibilities all over the SC activities (Nelson and Rao 2012). Among the various perspectives toward GSCM, Srivastava's view is one of the most cited definitions in academia. He defined GSCM as a form of supply chain management in which environmental thinking is integrated into the different stages from product design and material sourcing, to the manufacturing processes and delivery of the final product to the customers, as well as taking care of the products after their end-of-life (Srivastava 2007). From a broader

\footnotetext{
* Corresponding author: Graduate School of Logistics, Inha University, 100 Inha-ro, Nam-gu, Incheon, 22212, Korea

Email: scm@inha.ac.kr
} 
point of view, GSCM includes green practices in purchasing, manufacturing and materials handling, distribution, marketing, as well as reverse logistics, in order to optimize waste and energy consumption (Hervani et al. 2005). Initiatives for packaging and waste reduction, as well as emission reduction, also play a significant role in achieving the goals of GSCM (Walker and McBain 2008). In addition to the environmental aspects of the above-mentioned green practices, they can also bring cost reduction and efficiency to companies and society in general.

Although research into SC activities was initiated decades ago, green studies only became an emerging topic in the current decade. There are a number of research papers which provide a systematic review of the published papers and theoretical contributions. However, studies on the practical aspects of this subject are quite scarce and, to the best of our knowledge, no papers have been published on the classification of GSCM practices from a practical point of view. Owing to the fact that there exists a lack of awareness about green initiatives, particularly among general managers and practitioners in the field of supply chain management (Kim and Choi 2013), there is a need to provide them with a broad image of GSCM and the relevant practices. This research seeks to contribute to the field by filling this gap. The remainder of this paper is organized as follows. Section 2 reviews the GSCM disciplines and briefly describes the categorization of the initiatives in each sector. In Section 3, green practices and applications in four well-known companies are described. The final section concludes this paper.

\section{GSCM - disciplines}

The main objective of GSCM practices is to reduce the negative environmental impacts and wastes in the different stages of the SC (Hervani and Sarkis 2005). Moreover, such practices can bring social and financial benefits in addition to the environmental advantages. Focusing on a single stage of the SC activities may expose the organization to undesirable performance degradation. Therefore, a joint effort by various entities in the SC is needed to create harmony. In this section, the different disciplines of GSCM, Green Product Design, Green Purchasing, Green Production, Green Packaging, Green Marketing, Green Logistics, and closed-loop SC, are briefly introduced, and the possible areas in which green practices can be applied are described.

\subsection{Green product design}

Environmentally conscious design (Green Design) is the first discipline in the above-mentioned category. The social and ecological aspects of the design, processing, and use of products are the main criteria in the design and manufacturing of a product in this discipline. It involves a set of activities, aiming at making a safer and cleaner factory, reducing the cost of disposal, minimizing the environmental and health risks, improving product quality at a lower cost, promoting a better public image, and enhancing productivity. It can also provide manufacturers with the opportunity to minimize waste and to turn scrap items into a profitable product (Zhang et al. 1997). Initiatives in green design can be broadly classified into two major sub-categories entitled environmentally conscious product design and environmentally conscious process design (Kuo 1997). Design for the Environment (DFE) is one of the relevant topics, which is a systematic approach to designing products and processes in such a way as to address environmental concerns. DFE consists of two groups, namely design for sustainability and design for health and safety (Frazier 1996). Some of the green practices and corresponding disciplines are shown in Table 1.

\subsection{Green purchasing}

Green purchasing is a way of using the company's power as a consumer of raw materials to benefit the environment by buying products with less environmental impact. Large organizations can make a significant contribution to improve human health and the environment when they establish and follow a Green purchasing policy, which obliges their suppliers to provide eco-friendly products and services. There are various practices in this discipline, which are mostly emerging due to the passing of new regulations.

There are several factors that should be taken into consideration in order to purchase materials in a 'Green' way. First of all, it should be checked whether the product is made of the least possible amount of virgin materials. The energy consumption of the product is another significant factor. Moreover, the product must be durable and there should be possibilities to recycle it at the end of its life cycle. On the other hand, the packaging style should be optimum. Finally, the least possible amount of toxic substances should be used in the production process. In general, Green purchasing activities can be categorized into the following major approaches:

- Purchasing standard/eco-labeled products or services, which are confined to a specified threshold of environmental performance

- Evaluating products and services by in-house and/or third party evaluators prior to buying them

- Assisting suppliers to improve their operations, products and services

\subsection{Green manufacturing}


Green Manufacturing' refers to production systems that are highly efficient and cause little or no waste and pollution. This category is related to "Green design" to some extent. A range of waste materials can be produced as a consequence of inefficient manufacturing processes. Defective items including scrap and reworked materials, as well as overproduced items as the result of a build to stock policy are among the most common wastes that should be avoided. As another example, unnecessary movements by labors during the manufacturing process or holding work in process materials, and excessive inventory of raw materials are among the most common pitfalls. Using eco-friendly materials like green lubricants in the manufacturing process can also be mentioned in this group of green activities.

\subsection{Green marketing}

Green marketing can be defined as the process of selling merchandise based on its environmental benefits. A product can be eco-friendly due to its being produced by a green production process or being packaged in an environmentally friendly way. However, green marketing plays a significant role in influencing the buyer's decision and directing their attention toward 'green' products and services. By doing so, consumers may be willing to pay more to buy an eco-friendly product than a cheaper non-green alternative Green marketing includes various activities ranging from the modification of the product's appearance and packaging to its advertisement. Different terminologies have been used to name this area, among which Sustainable Marketing, Green Marketing, Environmental Marketing and Ecological Marketing are the most widely used. Targeting, green positioning, green pricing, marketing waste, green promotion and green alliance are among the major initiatives taking place in this discipline of GSCM practices (Grundey and Zaharia 2008).

Table 1. Green design practices by Zhang et al. (1997)

\begin{tabular}{|c|c|}
\hline Sub-discipline & Practices \\
\hline Design for Recovery and Reuse & $\begin{array}{l}\text { Design for material recovery } \\
\text { Design for component recovery }\end{array}$ \\
\hline Design for Disassembly & $\begin{array}{l}\text { Facilitate access to components } \\
\text { Simplify component interfaces } \\
\text { Design for simplicity }\end{array}$ \\
\hline Design for Waste Minimization & Design for source reduction \\
\hline Design for Separability & $\begin{array}{l}\text { Facilitate identification of materials } \\
\text { Use fewer types of materials } \\
\text { Use similar or compatible materials }\end{array}$ \\
\hline Design for Energy Conservation & $\begin{array}{l}\text { Reduce energy use in production } \\
\text { Reduce device power consumption } \\
\text { Reduce energy use in distribution } \\
\text { Use renewable forms of energy }\end{array}$ \\
\hline Design for Material Conservation & $\begin{array}{l}\text { Design multi-functional products } \\
\text { Specify recycled materials } \\
\text { Specify renewable materials } \\
\text { Use re-manufactured components } \\
\text { Design for product longevity } \\
\text { Design for closed-loop recycling } \\
\text { Design for packaging recovery } \\
\text { Design reusable containers } \\
\text { Develop leasing programs }\end{array}$ \\
\hline Design for Chronic Risk Reduction & $\begin{array}{l}\text { Reduce production releases } \\
\text { Avoid toxic/hazardous substances } \\
\text { Avoid ozone-depleting chemicals } \\
\text { Use water-based technologies } \\
\text { Assure product biodegradability } \\
\text { Assure waste disposability }\end{array}$ \\
\hline Design for Accident Prevention & $\begin{array}{l}\text { Avoid caustic/flammable materials } \\
\text { Provide pressure relay } \\
\text { Minimize leakage potential } \\
\text { Use childproof closures } \\
\text { Discourage consumer misuse }\end{array}$ \\
\hline
\end{tabular}




\subsection{Green logistics}

Logistics can be considered as the most important element of the SC process, as it represents the most significant portion of its negative environmental impact. Green initiatives are applicable in different logistical elements of the SC, from the acquisition of raw materials and inbound and outbound transportation to facility location/building design and warehousing. The green practices in this discipline can be categorized into three major groups:

The first is reducing the environmental impact of freight transportation. Transportation is the major source of negative environmental effects, such as pollution, noise and congestion. Therefore, sound planning in this area, comprising the proper selection of transportation modes and fuel type, the scheduling of deliveries and consolidation of shipments, can considerably diminish these environmental problems. The decisions in this regard are highly dependent on factors such as external influences, company demographics and the available technology (Kam et al. 2006).

The second is minimizing the effects of warehousing on the area surrounding the facilities. Warehousing and inventory management, as the other major element of logistics, are more than simply having the right amount of stock on the shelf, and this can exert various negative impacts on the environment. Eliminating waste, removing efficiencies, and lowering tangible and intangible costs are among the significant outcomes of a good inventory planning system.

The third is managing the return flow of waste. Although this category is basically related to logistics activities, the broad extent of the activities conducted in this part of the SC warrant its consideration as a separate element in the following section.

\subsection{Closed-loop supply chain}

The closed-loop SC has been defined in different ways and from various perspectives. In general, it comprises the design, control and operation of a SC, aiming at the maximization of the value produced by a product during its entire life cycle. The major focus of this discipline is all about taking back used products from the final consumer, assessing their quality and returning them to the SC process accordingly. As shown in Figure 1, the simultaneous consideration of forward and reverse flows results in a closed-loop SC. Forward flow consist of new products and/or raw materials and reverse flows consist of the used products, as well as re-manufactured/refurbished items. Remanufacturing, as one of the main options after product assessment, is the process of restoring a used product to a common operating and aesthetic standard, which may even involve upgrades in terms of functionality (Souza 2013).

Decisions in a closed-loop SC can be made at the strategic, tactical and operational levels. Strategic decisions, such as network design and collection strategies, have a long-term impact on the firm's operations, while other decisions, such as tactical and operational ones regarding inventory policies, are likely to affect them for a shorter period of time.

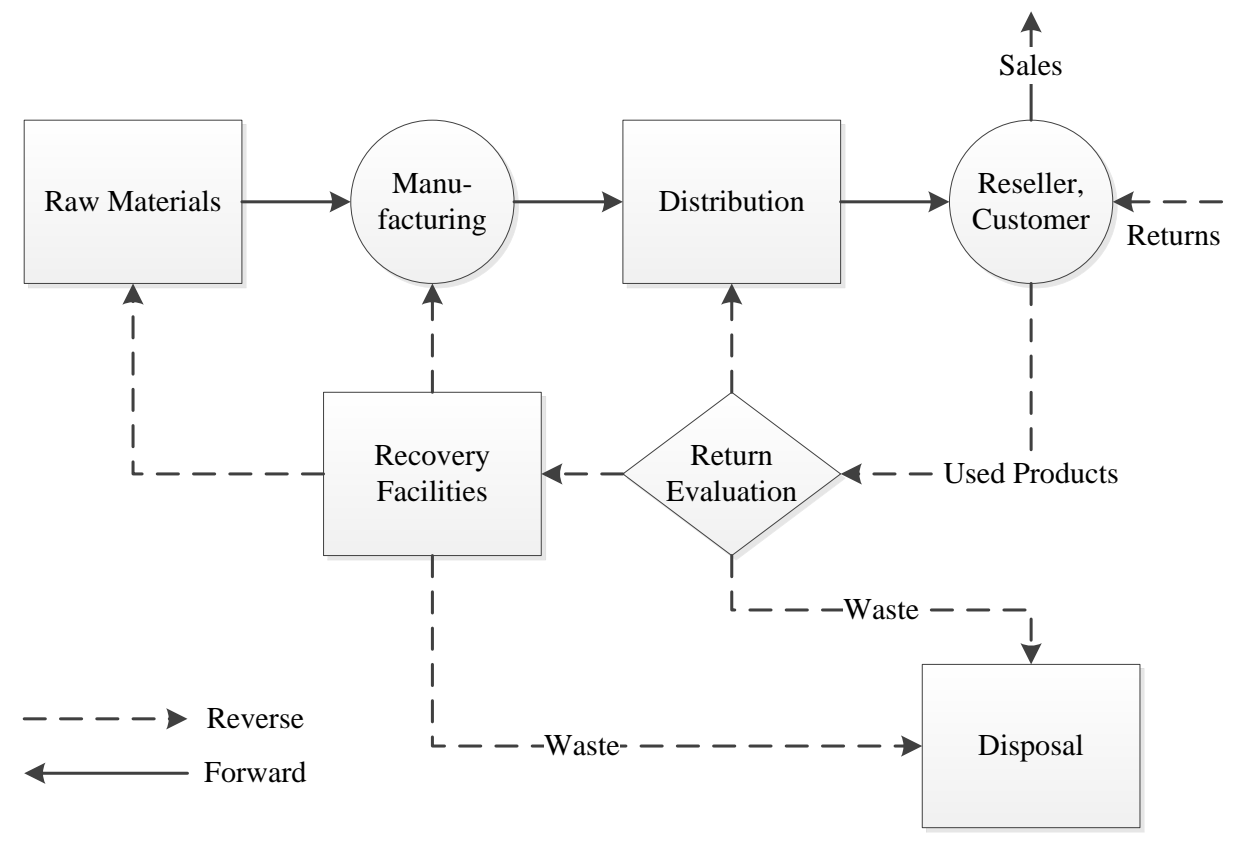

Figure 1. Forward/reverse logistics (Tonanont 2009) 


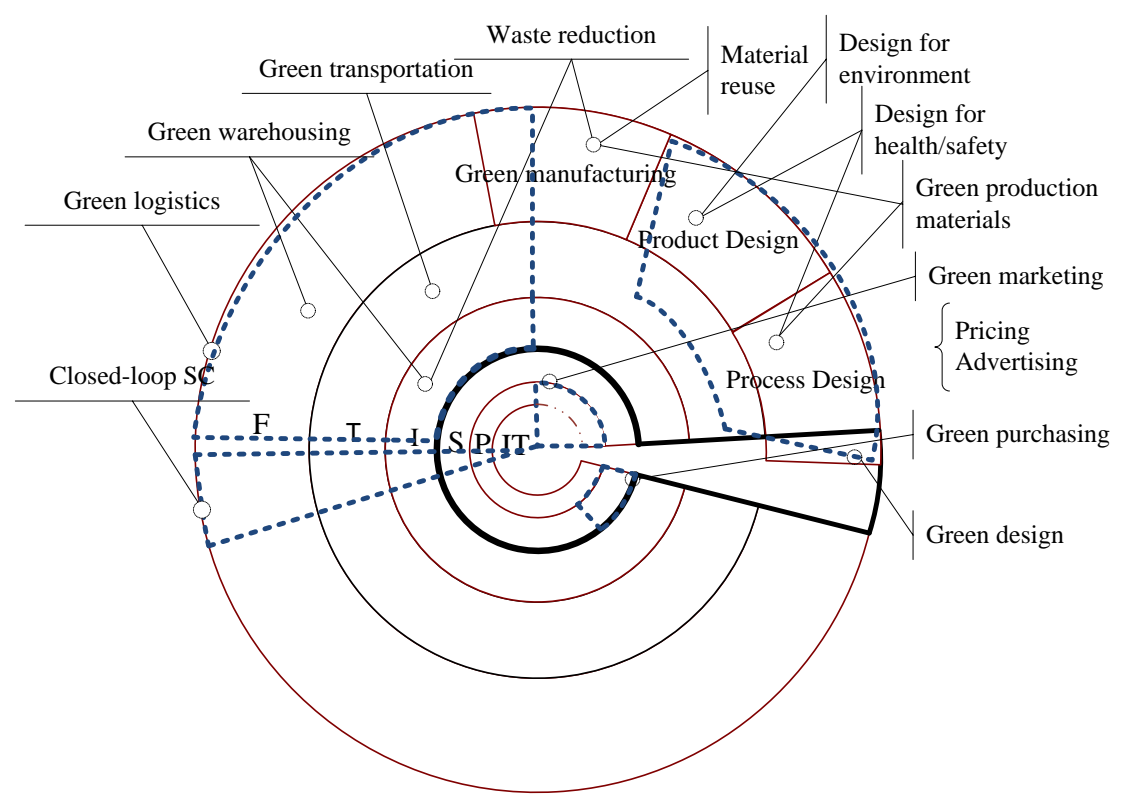

Figure 2. GSCM elements and disciplines (F: Facility, T: Transportation, I: Inventory, S: Sourcing, P: Pricing, IT: Information)

\section{GSCM - best practices}

Best practices in GSCM refer to a range of initiatives implemented by companies in order to decrease the negative environmental impact of their SC activities. According to the classification suggested by (Zhu and Sarkis 2004), GSCM activities consist of a number of main areas, viz. the Internal environmental management, Green purchasing, Customer cooperation (in environmental activities), Investment recovery, and Eco-design dimensions. These practices are summarized in Figure 2, where the scope of each of the initiatives discussed in the previous section is specified based on the elements of the SC (Chopra 2007). From another point of view, all of the initiatives can be generally categorized into internal and/or external oriented activities. Internal programs comprise activities such as implementing environmental management systems and investment recovery, which must basically be held in the focal company, whereas, in the latter category, several organizations must be taking part in the process, i.e. green purchasing and co-operation with customers for green packaging. On the other hand, green activities can be grouped into monitoring programs and collaboration programs (Perotti et al. 2012).

In this section, some of the best practices in five well-known companies will be described. Firstly, Fujitsu's major green activities will be introduced. A summary of the green initiatives of two other leading consumer electronics companies, Apple and Dell, will come next. The latter part is about the green practices in the parcel delivery company DHL.

\subsection{Fujitsu Ltd.}

Fujitsu Ltd. is a multi-national IT and consumer electronics company headquartered in Tokyo, Japan. The company's green activities were initially started in 2003 , with most of the initiatives being formed around the green logistics area. After the adoption of the Kyoto Protocol, Japan's government set a goal of decreasing its greenhouse gas emissions by $6 \%$ before 2010. Due to the significant contribution of the transportation sector in this respect, the government announced new regulations in 2006, which obliged shippers to adjust their operations to comply with the new energy saving policies. In response, a green logistics committee was established in 2006 by Fujitsu, compelling all of the environment-related departments to work with the logistics division. The Green logistics Committee's scope of action was defined in such a way as to involve the entire SC, from parts procurement to product delivery and recovery, all with the aim of reducing the company's negative environmental effects. In cooperation with transporters, the company aimed at greening the whole of the SC, from packaging to efficient storage and transport operations.

There is a wide array of green initiatives which are being performed in the company, among which rationalizing its distribution centers, optimizing the transportation distance and reducing the number of trucks are the most important. Fujitsu's new policies, including its modal shift and vehicle allocation programs, have notably decreased the amount of emissions resulting from its transportation activities. In the modal shift program, for instance, the company initially 
started switching from airplane and truck transport to railway and ship transport, in order to reduce its environmental load.

Implementing a modal shift strategy may impose additional costs, increase lead times and reduce the quality of the service. However, Fujitsu investigated the application of such a modal shift based on the distance and quantity of goods in order to offset these effects. The company also provides a variety of options for its customers to satisfy their specific preferences in terms of delivery time.

Prior to the implementation of these green initiatives in Fujitsu, each division of the company and its suppliers/retailers used to allocate vehicles and deliver merchandise individually. The dispersion of distribution centers and use of various data formats led to lots of inefficiencies. To resolve these problems, Fujitsu began to build a comprehensive optimization system with the goal of improving its environmental performance (Niwa 2014). The optimization system has several missions, of which the re-configuration of the facilities network, specifically the rationalization of the distribution centers, is probably the most challenging one. However, the standardization of the shipping instructions and amendment of the operating systems are more technical and require considerable expertise. The further reduction of $\mathrm{CO}_{2}$ emissions via the Fujitsu logistics solution system is another notable mission in this respect. The system formally began operating in February 2007 in pilot mode limited to the Tokyo area. At the time, the distribution centers were in the process of being relocated to three optimal locations. Information on cargo and shipping were standardized among partners and the focal company. The vehicle allocation system resumed working based on the shared information, where a traffic control system was employed to apply an eco-driving routing. The most recent green initiative in Fujitsu is the development of $\mathrm{a} \mathrm{CO}_{2}$ exhaust estimation tool. Decreasing the number of trucks by intensive vehicle-allocation control, installation of in-vehicle terminals in trucks, implementing eco-drive practices, and building an accurate emission calculator in trucks are some of the other initiatives in this regard.

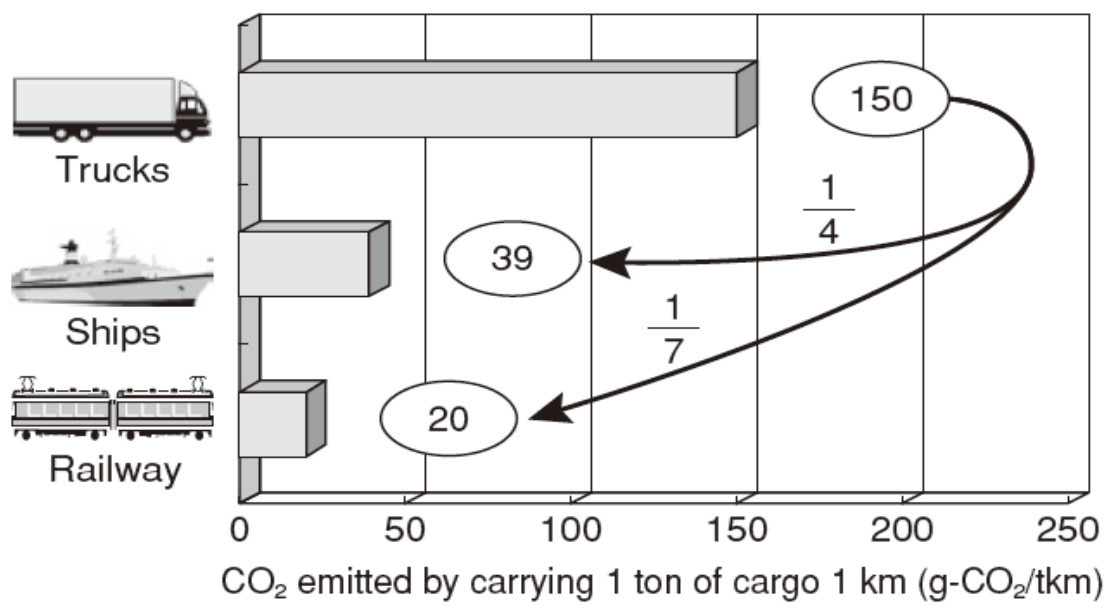

Figure 3. $\mathrm{CO}_{2}$ emission by type of transportation (extracted from the report by the Japanese ministry of land, infrastructure and transport on countermeasures against global warming in the transport sector)

\subsection{Apple Inc.}

Apple is an American company headquartered in California, the United States, founded in 1976. The company designs and produces consumer electronics and computer software and provides online services. It has striven to create eco-friendly products in different ways. According to Apple's Environmental Responsibility and footprint Report, they have set three priorities for green initiatives:

- Replacing conventional energy sources by renewable energies to reduce the impact of climate change

- Using environmental friendly materials in the manufacturing of Apple products

- Conserving precious resources by employing new production/design strategies

Apple initiated green practices in a broader range of activities compared to the above Japanese company. Referring to the environmental responsibility report that was published by Apple in 2014, the outstanding green initiatives in the company are briefly described in this section.

Facilities. The green design of new buildings and updating of existing facilities to take their energy efficiency into consideration is probably the most significant greening initiative by the company. The goal is to provide all of the 
network facilities with energy from renewable sources. The company is also making effort to provide on-site energy production, including solar, directed bio-gas fuel cells, and micro-hydro. Moreover, they have formed partnerships with third-party energy suppliers of renewable energies. In the light of the above-mentioned initiatives, Apple has achieved an energy savings of 30 percent at its data centers, corporate facilities and retail stores. The largest non-utility solar array and fuel cell facilities in the U.S. are constructed by Apple. However, in some cases, Apple accomplishes the remaining requirements with grid-purchased renewable energy and/or buying renewable energy credits (RECs). In a nutshell, the company's facilities in Cupertino and Elk Grove, California; Austin, Texas; Munich, Germany; and Cork, Ireland are being fully supplied by renewable energy.

Energy usage of products. Apple has started working on three major approaches to reduce its product's energy consumption in accordance with the green product design discipline: "more efficient power supplies to bring electricity from the wall to the device", "more efficient hardware", and "smarter power management software". The outcomes may seem negligible, but when the cumulative amount of energy saved in Apple devices is calculated, it can bring a notable reduction in its carbon footprint. Since 2008, Apple has reduced the average total power consumption in its products by 57 percent, which is beyond the threshold set by the U.S. Environmental Protection Agency for energy efficiency.

Transportation. Apple has attempted to minimize the environmental impact of employee commutes, inter-office trips, and business travel through green logistics initiatives. The company provides all employees with a transit subsidy. It also encourages its employees by offering preferred parking spaces for ride shares. More than 2,100 employees inside Apple's plants are using biodiesel-powered coaches, helping to avoid 6,377 metric tons of $\mathrm{CO}_{2}$ emissions. Apple also provides more than 300 electric vehicle charging ports, at no cost, and is adding more to fulfill the increasing demand. By doing so, Apple decreased its $\mathrm{CO}_{2}$ emissions in 2013 by 59 percent compared to those of 2012.

Merchandise and materials shipment. As another green design initiative, Apple has attempted to make lighter and more material-efficient products and packages, to conserves resources and, in turn, minimize its carbon footprint. For example, it established a policy to package the iPhone 5s, so that it is 41 percent smaller than the former design, and also reform the iMac packaging in such a way as to load more of the product on each pallet. Such initiatives can indirectly decrease the emissions resulting from transportation activities.

Recycling. Due to the fact that electronic waste can cause serious environmental issues, all Apple Stores follow the company's take-back policy for its products, in order to form a closed-loop SC. In regions with no take-back services, Apple has arranged for the pickup and delivery of the returned products. Surprisingly, these initiatives are not limited to Apple products however. In 2010, Apple attained a worldwide recycling collection of 70 percent of the overall amount of its previously sold products.

Removing toxins. Green manufacturing processes can remarkably reduce toxins in products. Apple is applying its own standards to stop using toxins which are potentially dangerous for the environment. Apple's power cords are being produced with no PVC or phthalate. Their touch screens are being manufactured with no arsenic and their cases and enclosures are BFR-free. In Apple, toxins are controlled not only in the products, but also in the production process. The Regulated Substances Specification in Apple obliges its suppliers to demonstrate compliance by subjecting them to third-party performance assessments.

\subsection{Dell Inc.}

Dell is a privately owned American company headquartered in Texas, the United States. The company, which provides repair services and sells computers and related products, was founded in 1984. Dell ships products to over 180 countries worldwide. The company implements a wide array of green initiatives. According to the company's report on its green logistics activities in 2014, Dell has aimed at minimizing waste by persistently refining the processes and tools it uses, in order to make the most efficient use of air, land and ocean transportation for receiving supplies, shipping products, delivering services, and accepting returns. In the case of modal selection, the company has applied new transportation modes and routes for shipments from Asia to Europe and from China to South Asia. Shifting its international shipments from aircraft to ocean freight has been the other major effort in this regard. Dell has also implemented many innovative strategies to minimize its transportation activities so as to decrease fuel consumption and carbon emissions. As one of the above-mentioned approaches, they implemented a plan to finalize retail orders closer to their end customers and consolidate them into less frequent shipments, which in turn reduces truckload volumes and fuel consumption. Dell has also conducted Container Optimization initiatives to improve the processes for pallet building and trailer loading. In its packaging department, Dell uses bamboo packaging for lightweight consumer products and mushroom-based packaging for heavier products. They have also attempted to reduce the volumes of paper used in the shipping of products through green design and packaging. Dell has also established initiatives to recycle packaging/protective dunnage in each regional logistic center. As one of the most recent green initiatives in its 
closed-loop SC program, the company has made 94 percent of the returned assets available for resale in its outlets. The returned products are being resold as certified refurbished items.

Dell collaborates with its partners in various ways to form green purchasing initiatives. They outsourced their shipment activities to logistics and transportation companies such as DHL, FedEx, and UPS, which are known to offer eco-friendly activities. This last initiative can also be considered as a green marketing effort to improve the image of the company. Many of Dell's partners have been asked to comply with the standards of ISO 14001, which in turn helps to improve the environmental performance in the SC as a whole. Electronically transmitting the shipping documents as well as using recycled cardboard dunnage for the necessary paper works is the other remarkable green practice in Dell.

\subsection{DHL Express}

DHL Express is a division of Deutsche Post DHL, a German logistics company which was founded in 1969. This company can be considered as the largest logistics company applying green initiatives and a front runner in this field. Since the majority of the activities in DHL center around delivering mail and parcels, green logistics and transportation initiatives constitute the core of DHL's green activities, which in turn can reduce a considerable portion of its $\mathrm{CO}_{2}$ emissions. A report on the green activities of DHL under the Go-Green program demonstrates that the company has implemented numerous green initiatives to cope with its environmental inefficiencies. In addition to green transportation and warehousing, the greening of its packaging practices and related activities in its marketing programs are among the major items which can be mentioned in this regard. The Go-Green environmental protection program is one of the recent green activities of DHL. The company targets a reduction of $30 \%$ in its $\mathrm{CO}_{2}$ emissions by the year 2020, compared to the 2007 norms. Such a plan requires several steps to be taken, among which determining and controlling the emissions of its subcontractors play a significant role. To do so, the company established an independent organization which is responsible for the process of collection, compilation and publication of the data

The company established a systematic approach for the optimization of its SC activities, in order to improve its operational performance in terms of environmental measures. Dynamic route planning, the consolidation of shipments, minimization of empty runs through freight backloads, maximal capacity usage, modal shifts and moving air freight to road and rail are among the efforts which have been made in developing these green logistics initiatives.

DHL has invested in a number of infrastructural upgrades, from employing smart trucks and aerodynamic vehicles, and applying modifications to motors, to the modernization of its buildings. In 2011, over 130 electric vehicles were added to the fleet of DHL's transportation system, which aimed at the reduction of any type of externalities. Replacing conventional fuels by biofuel sources is also contributing a lot to the company's environmental friendly performance. As the other major activity in this regard, DHL has assigned a budget to reduce the carbon footprint of its facilities by replacing its lighting and energy control systems, applying energy efficiency standards in the green design and construction of new buildings, and the installation of modern supplements for the use of sustainable resources. The installation of a photovoltaic system with solar cells and utilization of an innovative system to collect and store rainwater to cover a considerable amount of the facility's water needs are just some of the examples in the above-mentioned area.

\section{Conclusion}

Adhering to recent environmental legislation, i.e., the defined road map of the European commission for a 20 percent reduction in greenhouse gasses by the year 2020, the greening of SC activities has become vital for firms that want to survive and stay competitive. Not only the major polluting countries like China, but also countries that are polluting below the standards, have joined this global movement to reduce these emissions (Kim et al. 2010). As a matter of fact, the green SC topic has attracted the attention of practitioners in various fields during the past few years. This research sought to classify the GSCM disciplines and best practices from a practical point of view to contribute to this trend. According to this article, the initiatives of GSCM can be generally classified into green design, green purchasing, green production, green marketing, green logistics and closed-loop SC. This brief review of four companies' GSCM practices disclosed the superiority of Apple in implementing green practices, particularly in the manufacturing area. The implementation of practices for the further reduction of defects, waiting times, overproduction, excessive inventories and complexity of products are worthwhile recommending to the companies mentioned in this report, in order for them to achieve a sustainable SC. In the green marketing group of initiatives, Dell has performed the best compared to the other cases. Developing a green brand besides the original brand, promoting Eco campaigns, or replacing the corporate's logo with a green-based emblem are among the actions which could be recommended to the other two consumer electronics and IT companies to further improve their brand's image. Green purchasing practices have also been well employed by Dell, while Apple is the leading company in green design and manufacturing. On the other hand, logistics initiatives have been well implemented by all of the reviewed companies, especially by Fujitsu and DHL. Dell and Apple have established a good reputation in terms of applying closed-loop SC, which has helped them to build a green corporate image for themselves. 


\section{References}

Beamon, B.M., 1999. Designing the green supply chain. Logistics Information Management, 12, 332-342.

Chopra, S., 2007. Supply Chain Management. 3rd Eds. Pearson Education. Edinburgh, UK.

Frazier, R.R., 1996. Overcoming middle management resistance to strategic change: design for environment (DEF) at Xerox. Master Thesis, Massachusetts Institute of Technology.

Göttlicher, S., 2012. Gogreen program. < http://www.trailblazer.eu/files/249996706.pdf>.

Grundey, D., Zaharia, R.M., 2008. Sustainable incentives in marketing and strategic greening: the cases of Lithuania and Romania. Technological and Economic Development of Economy 14, 130-143.

Hervani, A.A., Helms, M.M., Sarkis, J., 2005. Performance measurement for green supply chain management. Benchmarking: An International Journal 12, 330-353.

Kam, B.H., Christopherson, G., Smyrnios, K.X., Walker, R.H., 2006. Strategic Business Operations, Freight Transport and Ecoefficiency: A Conceptual Model, Greenleaf, Sheffield.

Khidir, T.A., Zailani, S.H.M., 2006. Greening of the supply chain through supply chain initiatives towards environmental sustainability. < http://www.jgbm.org/page/30\%20Suhaiza\%20Zailani\%20.pdf>.

Kim, H., Choi, J., 2013. Third-party enterprises' perceptions of green logistics in China. Journal of International Logistics and Trade $11,27-42$.

Kim, M.J., Hong, S.J., Ha, H.K., 2010. An estimation of gas emissions in Korea's air transport industry. Journal of International Logistics and Trade 8, 117-140.

Kuo, T.C., 1997. A disassembly model for end-of-life products recycling. PhD Thesis, Texas Tech University.

Melville, N.P., 2010. Information systems innovation for environmental sustainability. MIS Quarterly 34, 1-21.

Nelson, D., Marsillac, E., Rao, S., 2012. Antecedents and evolution of the green supply chain. Journal of Operations and Supply Chain Management Special Issue 1, 29-43.

Niwa, K., 2014. Fujitsu group's green logistics activities. Fujitsu Scientific \& Technical Journal 50, 99-103

Perotti, S., Zorzini, M., Cagno, E., 2012. Green supply chain practices and company performance: the case of 3PLs in Italy. International Journal of Physical Distribution \& Logistics Management 42, 640-672

Souza, G.C., 2013. Closed-loop supply chains: a critical review, and future research. Decision Sciences 44, 7-38.

Srivastava, S.K., 2007. Green supply-chain management: a state-of-the-art literature review. International Journal of Management Review 9, 53-80.

Tonanont, A., Yimsiri, S., Jitpitaklert, W., 2008. Performance evaluation in reverse logistics with data envelopment analysis. Proceedings of Industrial Engineering Research Conference, 764-769.

Walker, H., Sisto, L.D., McBain, D., 2008. Drivers and barriers to environmental supply chain management practices: Lessons from the public and private sectors. Journal of Purchasing and Supply Management 14, 69-85.

Zhang, H.C., Kou, T.C., Lu, H., 1997. Environmentally conscious design and manufacturing: a state-of-the-art survey. Journal of Manufacturing Systems 16, 352-371.

Zhu, Q., Sarkis, J., 2004. Relationships between operational practices and performance among early adopters of green supply chain management practices in Chines manufacturing. Journal of Operations Management 22, 265-289. 